\title{
Effect of COVID-19 on delivery plans and postnatal depression scores of pregnant women
}

\author{
PW Hui *, Grace Ma, Mimi TY Seto, KW Cheung
}

This article was published on 5 Nov 2020 at www.hkmj.org.

\section{A B S T R A C T}

Introduction: Owing to the coronavirus disease 2019 outbreak Hong Kong hospitals have suspended visiting periods and made mask wearing mandatory. In obstetrics, companionship during childbirth has been suspended and prenatal exercises, antenatal talks, hospital tours, and postnatal classes have been cancelled. The aim of the present study was to investigate the effects of these restrictive measures on delivery plans and risks of postpartum depression.

Methods: We compared pregnancy data and the Edinburgh Postpartum Depression Scale (EPDS) scores of women who delivered between the pre-alert period (1 Jan 2019 to 4 Jan 2020) and post-alert period (5 Jan 2020 to 30 Apr 2020) in a tertiary university public hospital in Hong Kong. Screening for postpartum depression was performed routinely using the EPDS questionnaire 1 day and within 1 week after delivery.

Results: There was a $13.1 \%$ reduction in the number of deliveries between 1 January and 30 April from 1144 in 2019 to 994 in 2020. The EPDS scores were available for 4357 out of 4531 deliveries (96.2\%). A significantly higher proportion of women had EPDS scores of $\geq 101$ day after delivery in the post-alert group than the pre-alert group (14.4\% vs $11.9 \%$; $\mathrm{P}<0.05)$. More women used pethidine $(6.2 \%$ vs $4.6 \%)$ and fewer used a birthing ball (8.5\% vs $12.4 \%)$ for pain relief during labour in the post-alert group.

Conclusions: Pregnant women reported more depressive symptoms in the postpartum period following the alert announcement regarding coronavirus infection in Hong Kong. This was coupled with a drop in the delivery rate at our public hospital. Suspension of childbirth companionship might have altered the methods of intrapartum pain relief and the overall pregnancy experience.

\section{Hong Kong Med J 2020;26:113-7 \\ https://doi.org/10.12809/hkmj208774 \\ PW Hui *, MD, FRCOG \\ G Ma, MHSM (Health Services Management) \\ MTY Seto, MB, BS, MRCOG \\ KW Cheung, MB, BS, MRCOG}

Department of Obstetrics and Gynaecology, Queen Mary Hospital, Pokfulam, Hong Kong

* Corresponding author: apwhui@hku.hk

New knowledge added by this study

- The delivery rate at a public hospital was reduced during the coronavirus disease 2019 (COVID-19) pandemic.

- Women who delivered in the public hospital had higher Edinburgh Postnatal Depression Scale scores during the coronavirus alert period.

- A lower rate of non-pharmacological pain relief and a higher rate of pethidine usage were observed during labour.

Implications for clinical practice or policy

- Obstetricians should be aware of the psychological burden of the COVID-19 outbreak on pregnant women, especially in the immediate postpartum period.

- Alternative measures and effective intervention should be available to support these women during this pandemic crisis.

\section{Introduction}

The outbreak of coronavirus disease 2019 (COVID-19) leads to a declaration of a serious level of response on 4 January 2020, which was escalated to the emergency level on 25 January 2020.1,2 Corresponding policies were imposed by the Hospital Authority at that time. Visiting periods were suspended, and mask wearing became mandatory in hospitals. In obstetrics, companionship during childbirth was stopped, as were visits to newborns staying with mothers in the postnatal ward. All prenatal exercise, antenatal talks, hospital tours, and postnatal classes were cancelled. The infection continued to spread worldwide, and a pandemic was declared by the World Health Organization on 11 March 2020. The first case of a COVID-19-infected pregnant mother was confirmed on 20 March 2020. The Hong Kong Government has further restricted travel and tightened social distancing and other measures to limit the spread of COVID-19.

Increased psychological stress and anxiety levels have been reported in countries with major 


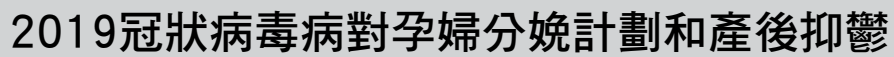 評分的影響 \\ 許佩華、馬家儀、司徒天欣、張嘉宏}

引言：2019冠狀病毒病爆發令香港醫院暫停就診時間並實行強制戴口 罩措施。產科暫停陪伴分娩, 產前運動、產前面談、參觀醫院和產後 課程亦因而取消。本研究檢視這些限制措施對分娩計劃和產後抑榣風 險的影響。

方法: 我們將一所大學教學醫院的產婦於香港啟動嚴重應變級別前 （2019年1月1日至2020年1月4日）和發出嚴重應變級別後（2020年 1 月 5 日至 2020 年 4 月 30 日）的妊娠數據和愛丁堡產後抑鬱量表 （EPDS）評分作比較, 並以EPDS問卷進行分娩後 1 天和 1 週內產後抑 缶篩檢。

結果：本院的分娩數字由 2019 年1月1日至4月30日的 1144 例，下跌 $13.1 \%$ 至 2020 年同期的994例。在4531例分娩中取得4357例EPDS 評分（佔96.2\%）。與啟動嚴重應變級別前相比, 發出嚴重應變級別 後婦女的產後 1 天EPDS評分為 10 或以上的比例顯著較高 $(14.4 \%$ 比 $11.9 \% ; \mathrm{P}<0.05$ ）。與啟動嚴重應變級別前比較, 發出嚴重應變級別 後分婏婦女使用哌替啶的比例較高（4.6\%比6.2\%），使用分娩球的比 例則較低 $(8.5 \%$ 比 $12.4 \%)$ 。

結論 : 香港啟動2019冠狀病毒病嚴重應變級別後, 較多婦女出現產後

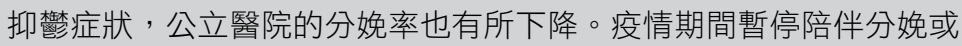
會改變婦女分娩時使用的鎮痛方法和影響其分娩經歷。

outbreaks. ${ }^{3,4}$ As reflected by the Edinburgh Postnatal Depression Scale (EPDS), pregnant women assessed after the declaration of the COVID-19 epidemic had significantly higher rates of depressive symptoms than women assessed before the announcement in China. ${ }^{5,6}$ Behavioural changes have also been recognised among pregnant women. ${ }^{7}$ This evolving situation and its concomitant alterations in obstetric care can potentially pose extra psychological stress during the peripartum period.

In our university-affiliated tertiary hospital in Hong Kong, screening for women at risk of or having emotional problems is performed for all pregnancies antenatally during a booking visit. Counselling and support are provided by trained midwives and nurses from Comprehensive Child Development Service to those in need. Postpartum depression is routinely assessed after delivery using the validated EPDS. ${ }^{8,9}$ The aim of the present study was to examine the effect of COVID-19 and its concurrent service adjustments on couples' obstetric planning and postpartum depression.

\section{Methods}

This was a retrospective study of the delivery data and EPDS scores of women who delivered at Queen Mary Hospital in Hong Kong from 1 January 2019 to 30 April 2020. Information related to the original number of bookings, actual deliveries, childbirth companionship, basic demographics, mode of delivery, epidural rate, and other methods of pain relief were retrieved from the Clinical Information System and Clinical Data Analysis and Reporting System of the Hospital Authority.

Screening for postpartum depression was performed routinely by asking all women to complete the EPDS questionnaire 1 day after delivery. This assessment was conducted again by phone within 1 week after delivery. The EPDS consists of 10 questions with a maximum score of 30 and has a validated Chinese version. ${ }^{9,10}$ A cut-off of $\geq 10$ was adopted locally. Women with high scores were counselled by a dedicated team of midwives and psychiatric nurses.

Comparisons of delivery data and EPDS scores were performed between women who delivered during the pre-alert period (1 Jan 2019 to 4 Jan 2020) and the post-alert period (5 Jan 2020 to 30 Apr 2020). Analysis was performed using SPSS (Windows version 25; IBM Corp, Armonk [NY], United States). Student's $t$ tests and Chi squared tests were used as appropriate with $\mathrm{P}<0.05$ considered as statistically significant.

\section{Results}

There were 1997 pregnant women with expected delivery dates between January 2020 and April 2020 booked for delivery at Queen Mary Hospital, as compared with 1869 bookings for the corresponding 4-month period in 2019. However, there was a $13.1 \%$ reduction in the number of actual deliveries between 1 January and 30 April, from 1144 in 2019 to 994 in 2020 . Fewer than half of the total number of women who originally booked for delivery in our hospital eventually delivered there, and the drop was more profound from February to April 2020. As a result, there were 3577 deliveries from 1 January 2019 to 4 January 2020 (ie, the pre-alert group) and 954 deliveries from 5 January 2020 to 30 April 2020 (ie, the post-alert group).

A significantly higher proportion of Chinese women $(85.1 \%$ vs $81.5 \%$; $\mathrm{P}<0.05)$ delivered during the post-alert period, while proportion of women with labour companionship was significantly reduced $(21.8 \%$ vs $88.8 \%$; $\mathrm{P}<0.05)$ compared with the pre-alert period. For pain relief during labour, more women received pethidine injections and fewer women used a birthing ball during the postalert period. The other parameters were comparable between the two groups (Table 1).

Out of 4531 total deliveries, EPDS scores were available for 4357 (96.2\%) 1 day after delivery and 3772 (83.2\%) within 1 week after delivery. A significantly higher proportion of women had EPDS scores of $\geq 101$ day after delivery in the post-alert group compared with the pre-alert group (14.4\% vs $11.9 \% ; \mathrm{P}<0.05)$. This proportion was reduced to $2.9 \%$ on the second assessment within 1 week of delivery, 
TABLE I. Background characteristics of women who delivered during the pre-alert (I Jan 2019 to 4 Jan 2020 ) and post-alert (5 Jan 2020 to 30 Apr 2020) periods*

\begin{tabular}{|c|c|c|c|}
\hline Period & Pre-alert & Post-alert & $P$ value \\
\hline Deliveries $(n=4531)$ & 3577 & 954 & \\
\hline \multicolumn{4}{|l|}{ Race } \\
\hline Chinese & $2914(81.5 \%)$ & $812(85.1 \%)$ & $<0.05 \dagger$ \\
\hline Non-Chinese & $663(18.5 \%)$ & $142(14.9 \%)$ & \\
\hline Maternal age (years) & $33.1 \pm 4.4$ & $33.1 \pm 4.6$ & NSł \\
\hline Gestational age (weeks) & $38.5 \pm 2.25$ & $38.5 \pm 2.29$ & NS $\ddagger$ \\
\hline Birthweight (g) & $3094 \pm 548$ & $3094 \pm 545$ & NS $\ddagger$ \\
\hline Nulliparous & $2006(56.1 \%)$ & $502(52.6 \%)$ & NS† \\
\hline Multiple pregnancies & $105(2.9 \%)$ & $25(2.6 \%)$ & NS† \\
\hline Mental problems under CCDS & $136(3.8 \%)$ & $39(4.1 \%)$ & NS† \\
\hline \multicolumn{4}{|l|}{ Mode of delivery } \\
\hline Normal vaginal delivery & $2175(60.8 \%)$ & $594(62.3 \%)$ & NS† \\
\hline Instrumental delivery & $378(10.6 \%)$ & $91(9.5 \%)$ & NS† \\
\hline Caesarean section & $1005(28.1 \%)$ & $262(27.5 \%)$ & NSt \\
\hline Labour companionship & $3177(88.8 \%)$ & $208(21.8 \%)$ & $<0.05 \dagger$ \\
\hline \multicolumn{4}{|l|}{ Pain relief method } \\
\hline Epidural & $461(12.9 \%)$ & $126(13.2 \%)$ & NS† \\
\hline Pethidine injection & $164(4.6 \%)$ & $59(6.2 \%)$ & $<0.05 \dagger$ \\
\hline Entonox & $2602(72.7 \%)$ & $688(72.1 \%)$ & NSt \\
\hline Non-pharmacological methods & $2851(79.7 \%)$ & $785(82.3 \%)$ & NSt \\
\hline Breathing & $2823(78.9 \%)$ & 779 (81.7\%) & NS† \\
\hline Warming pad & $7(0.2 \%)$ & 0 & NS† \\
\hline Birthing ball & $445(12.4 \%)$ & $81(8.5 \%)$ & $0.001 \dagger$ \\
\hline Massage & $620(17.3 \%)$ & $140(14.7 \%)$ & NS† \\
\hline Aromatherapy & $120(3.4 \%)$ & $43(4.5 \%)$ & NSt \\
\hline TENS unit & 935 (26.1\%) & 238 (24.9\%) & NS† \\
\hline
\end{tabular}

Abbreviations: CCDS = Comprehensive Child Development Service; NS = non-significant;TENS = transcutaneous electrical nerve stimulation

* Data are shown as No. (\%) or mean \pm standard deviation, unless otherwise specified

+ Chi squared test

$\ddagger$ tTest

at which point the scores became comparable with those of the pre-alert group (2.3\%).

Compared with the first assessment 1 day after delivery, women in both groups demonstrated significantly lower mean EPDS scores on the second assessment within 1 week (pre-alert group: 4.71 vs 1.36 ; post-alert group: 4.93 vs 1.42 ; $\mathrm{P}<0.01$ ). The mean EPDS scores obtained on both 1 day (4.93 vs 4.71$)$ and within 1 week (1.42 vs 1.36$)$ after delivery were higher following the declaration of alert response, although the difference was statistically insignificant. The monthly mean EPDS score 1 day after delivery was higher during the post-alert period (range, 4.87-4.99) than during the pre-alert period (4.71; 95\% confidence interval $=4.57-4.85$; Table 2 ).

\section{Discussion}

The present study is the first to report the impact of COVID-19 on obstetric care and postpartum depression in Hong Kong. The delivery rate in public hospitals has dropped dramatically in the post-alert period. This drop has been more profound since February 2020, especially among non-Chinese women. As of 30 April 2020, there had been three confirmed COVID-19 cases in pregnant women in Hong Kong. Although local changes in public health behaviour, social distancing, and isolation have largely contained the local outbreak of COVID-19, ${ }^{2}$ these policies could disrupt couples' delivery plans. The reduced delivery rate could represent a shift of childbirth from public hospitals to private ones that 
TABLE 2. EPDS results of women who delivered during the pre-alert and post-alert periods from I January 2019 to 30 April $2020 *$

\begin{tabular}{|c|c|c|c|c|c|c|c|}
\hline \multirow{2}{*}{$\begin{array}{l}\text { Alert status } \\
\text { Period }\end{array}$} & \multirow{2}{*}{$\begin{array}{c}\text { Pre-alert } \\
\text { (1 Jan } 2019 \text { to } \\
\text { 4 Jan 2020) }\end{array}$} & \multirow{2}{*}{$\begin{array}{c}\text { Post-alert } \\
\text { (5 Jan } 2020 \text { to } \\
30 \text { Apr 2020) }\end{array}$} & & \multicolumn{4}{|c|}{ Post-alert group: monthly intervals } \\
\hline & & & & Jan 2020 & Feb 2020 & Mar 2020 & Apr 2020 \\
\hline Deliveries $(n=4531)$ & 3577 & 954 & & 281 & 224 & 232 & 217 \\
\hline EPDS 1 day after delivery $(n=4357)$ & 3432 & 925 & & 275 & 221 & 225 & 204 \\
\hline EPDS <10 $(n=3814)$ & $3022(88.1 \%)$ & $792(85.6 \%)$ & & $231(84.0 \%)$ & $180(81.4 \%)$ & $199(88.4 \%)$ & $176(86.3 \%)$ \\
\hline EPDS $\geq 10(n=543)$ & $410(11.9 \%)$ & $133(14.4 \%)$ & $\mathrm{P}<0.05 \dagger$ & $44(16.0 \%)$ & $35(15.8 \%)$ & $26(11.6 \%)$ & $28(13.7 \%)$ \\
\hline Mean EPDS & 4.71 & 4.93 & NS $\ddagger$ & 4.94 & 4.87 & 4.93 & 4.99 \\
\hline $95 \% \mathrm{Cl}$ & $4.57-4.85$ & $4.66-5.21$ & & $4.42-5.47$ & $4.32-5.34$ & $4.39-5.47$ & $4.38-5.59$ \\
\hline EPDS 1 week after delivery $(n=3772)$ & 2970 & 802 & & 250 & 188 & 193 & 171 \\
\hline EPDS < $10(n=3680)$ & 2901 (97.7\%) & 779 (97.1\%) & & 241 (96.4\%) & $184(97.9 \%)$ & $186(96.4 \%)$ & 168 (98.2\%) \\
\hline EPDS $\geq 10(n=92)$ & $69(2.3 \%)$ & $23(2.9 \%)$ & NSt & $9(3.6 \%)$ & $4(2.1 \%)$ & 7 (3.6\%) & $3(1.8 \%)$ \\
\hline Mean EPDS & 1.36 & 1.42 & NS $\ddagger$ & 1.62 & 1.19 & 1.40 & 1.42 \\
\hline $95 \% \mathrm{Cl}$ & $1.27-1.45$ & $1.23-1.62$ & & $1.26-1.99$ & $0.86-1.53$ & $0.98-1.82$ & $1.01-1.82$ \\
\hline
\end{tabular}

Abbreviations: $95 \% \mathrm{Cl}=95 \%$ confidence interval; EPDS = Edinburgh Postpartum Depression Scale; NS = non-significant

* Data are shown as No. (\%), unless otherwise specified

$\dagger$ Chi squared test

$\ddagger t$ Test

did not manage suspected or confirmed COVID-19 patients. Non-Chinese women might have returned to their home countries out of fear of COVID-19. Women who deliver in public hospitals now increasingly have to face the challenge of childbirth without the companionship of family members and complete their hospital stay without visitors. All of these could account for the reduced delivery rate in the public sector.

Another important finding was the increased proportion of women with high EPDS scores in the post-alert period. We observed an increase in EPDS scores shortly after delivery during the post-alert period. This aligns with the findings of a multicentre study conducted in China following the announcement of human-to-human transmission. ${ }^{6}$ The COVID-19 pandemic could cause health anxiety and postpartum depression. ${ }^{7,11}$ Women of reproductive age in Hong Kong experienced the severe acute respiratory syndrome epidemic in 2002 to 2003 . Thus, these women are potentially more stressed than those in other countries. An emergency response was raised in Hong Kong even before the declaration of a pandemic by the World Health Organization. The practice of mask wearing has been widely adopted previously, and supplies have been in huge demand in the past. ${ }^{1}$ The memories of severe acute respiratory syndrome coupled with the abrupt changes in social behaviour during the post-alert period might have triggered more stress in pregnant women and been reflected in their EPDS scores. Moreover, those who remained in the public system might not have had alternative delivery options elsewhere. Pregnant women are vulnerable to postpartum depression, and early identification and effective intervention from Comprehensive Child Development Service might help to relieve these women's stress. These adverse effects could also potentially be ameliorated by the provision of online education materials, a lactation support hotline, early postnatal discharge, and family support.

Childbirth is a major life event for a family. Companions can provide information about childbirth, bridge communication gaps between healthcare workers and women, and facilitate non-pharmacological pain relief. They can also provide practical support, including encouraging women in labour to move around, providing massages, and holding their hands. ${ }^{12}$ The overall usage of non-pharmacological pain relief was similar between the pre- and post-alert periods. However, a significantly lower proportion of women used a birthing ball for pain relief during labour in the post-alert period, probably secondary to the suspension of childbirth companionship. Fewer women received childbirth massages, as they are usually provided by companions. Contrary to this, more women needed pethidine injections during labour. This indicates the contributory role of childbirth companionship to women's overall birthing experience.

The present study illustrates the impact of COVID-19 on pregnant women's delivery plans and the need for attention to their emotional disturbance. This is important information for obstetricians to consider during the revision and adjustment of service provision. Remedial measures like teleconferencing and early postnatal discharge can facilitate speedy recovery from distress. Although 
we noted increased levels of postnatal depression in the post-alert period, this study was not designed to study the contributory effects of COVID-19, cessation of childbirth companionship, or elimination of visiting hours to postnatal depression. Another limitation is the lack of data on anxiety levels, which could provide a more comprehensive picture of the pregnant women's emotional health. Moreover, this review is limited to the assessment of women who ultimately delivered in our hospital. Such women might be more adaptive and prepared for the altered environment than those who chose to give birth in the private sector or abroad. As the study was restricted to one public hospital, the findings might not be generalisable to hospitals in other catchment areas, which may have different population characteristics. The policies of restricted gathering and social distancing might affect the arrangements of family celebrations, baby showers, and the cultural practice of 'doing the month'. It will be of interest to examine whether women's stress and anxiety levels change during the later postnatal period. Further study is warranted to examine the social and psychological responses of pregnant women during the COVID-19 pandemic.

\section{Conclusion}

Measures to limit the spread of COVID-19 have resulted in fewer deliveries in our public hospital and more symptoms of postpartum depression. Obstetricians should be aware of these effects on the psychosocial well-being of pregnant women and offer timely intervention to provide stress relief.

\section{Author contributions}

Concept or design: All authors.

Acquisition of data: PW Hui, G Ma, MTY Seto.

Analysis or interpretation of data: PW Hui.

Drafting of the manuscript: PW Hui.

Critical revision of the manuscript for important intellectual content: All authors.

All authors had full access to the data, contributed to the study, approved the final version for publication, and take responsibility for its accuracy and integrity.

\section{Conflicts of interest}

All authors have disclosed no conflicts of interest.

\section{Acknowledgement}

The authors thank all midwives and nurses for their contributions to the assessment of postnatal depression in women who delivered at Queen Mary Hospital.

\section{Funding/support}

This research received no specific grant from any funding agency in the public, commercial, or not-for-profit sectors.

\section{Ethics approval}

This research has been approved by the Institutional Review Board of the University of Hong Kong/Hospital Authority West Cluster (HKU/HA HKW IRB; Ref UW 20-419).

\section{References}

1. Leung GM, Cowling BJ, Wu JT. From a sprint to a marathon in Hong Kong. N Engl J Med 2020;382:e45.

2. To KK, Yuen KY. Responding to COVID-19 in Hong Kong. Hong Kong Med J 2020;26:164-6.

3. Moghanibashi-Mansourieh A. Assessing the anxiety level of Iranian general population during COVID-19 outbreak. Asian J Psychiatr 2020;51:102076.

4. Ozamiz-Etxebarria N, Dosil-Santamaria M, PicazaGorrochategui M, Idoiaga-Mondragon N. Stress, anxiety, and depression levels in the initial stage of the COVID-19 outbreak in a population sample in the Northern Spain [in English, Spanish]. Cad Saude Publica 2020;36:e00054020.

5. Wang $C$, Pan R, Wan X, et al. Immediate psychological responses and associated factors during the initial stage of the 2019 coronavirus disease (COVID-19) epidemic among the general population in China. Int J Environ Res Public Health 2020;17:1729.

6. Wu Y, Zhang $\mathrm{C}$, Liu $\mathrm{H}$, et al. Perinatal depressive and anxiety symptoms of pregnant women along with COVID19 outbreak in China. Am J Obstet Gynecol 2020;223:240. e1-9.

7. Corbett GA, Milne SJ, Hehir MP, Lindow SW, O'Connell MP. Health anxiety and behavioural changes of pregnant women during the COVID-19 pandemic. Eur J Obstet Gynecol Reprod Biol 2020;249:96-7.

8. Leung WC, Kung F, Lam J, Leung TW, Ho PC. Domestic violence and postnatal depression in a Chinese community. Int J Gynaecol Obstet 2002;79:159-66.

9. Cox JL, Holden JM, Sagovsky R. Detection of postnatal depression. Development of the 10-item Edinburgh Postnatal Depression Scale. Br J Psychiatry 1987;150:782-6.

10. Lee DT, Yip SK, Chiu HF, et al. Detecting postnatal depression in Chinese women. Validation of the Chinese version of the Edinburgh Postnatal Depression Scale. Br J Psychiatry 1998;172:433-7.

11. Rashidi Fakari F, Simbar M. Coronavirus pandemic and worries during pregnancy; a letter to editor. Arch Acad Emerg Med 2020;8:e21.

12. Bohren MA, Berger BO, Munthe-Kaas H, Tunçalp Ö. Perceptions and experiences of labour companionship: a qualitative evidence synthesis. Cochrane Database Syst Rev 2019;(3):CD012449. 